\title{
The Mathematics Enthusiast
}

Volume 17

Numbers 2 \& 3

Article 11

$6-2020$

\section{The role of uncertainty in mathematical tasks for prospective elementary teachers}

Ziv Feldman

Megan Wickstrom

Sayonita Ghosh Hajra

Dittika Gupta

Follow this and additional works at: https://scholarworks.umt.edu/tme

Let us know how access to this document benefits you.

\section{Recommended Citation}

Feldman, Z., Wickstrom, M., Ghosh Hajra, S., \& Gupta, D. (June 2020). The role of uncertainty in mathematical tasks for prospective elementary teachers. In A. Appova, R. M. Welder, and Z. Feldman, (Eds.), Supporting Mathematics Teacher Educators' Knowledge and Practices for Teaching Content to Prospective (Grades K-8) Teachers. Special Issue: The Mathematics Enthusiast, ISSN 1551-3440, vol. 17, nos. 2 \& 3, pp. 641-672. ScholarWorks: University of Montana. Retrieve (open access) from: https://scholarworks.umt.edu/tme

This work is brought to you for free and open access by ScholarWorks at University of Montana. It has been accepted for inclusion in The Mathematics Enthusiast by an authorized editor of ScholarWorks at University of Montana. For more information, please contact scholarworks@mso.umt.edu. 
TME, vol. 17, nos. 2\&3, p.641

\title{
The Role of Uncertainty in Mathematical Tasks for Prospective Elementary Teachers
}

\author{
Ziv Feldman \\ Boston University, USA \\ Megan Wickstrom \\ Montana State University, USA \\ Sayonita Ghosh Hajra \\ California State University, Sacramento, USA \\ Dittika Gupta \\ Midwestern State University, USA
}

\begin{abstract}
Mathematics teacher educators (MTEs) charged with the content preparation of prospective elementary teachers (PTs) receive widespread recommendations on a variety of issues, including which mathematical topics to include in their courses, the types of pedagogical strategies to use when working with PTs, and how to foster the development of particular mathematical practices. The nature of the mathematical tasks that MTEs can use to best support and extend PTs' content knowledge is another area that deserves attention. This article considers uncertainty as a task feature and explains how it can be incorporated into mathematical tasks in order to support PTs' specialized content knowledge. Using Zaslavsky's (2005) three types of uncertainty - competing claims, unknown path or questionable conclusion, and non-readily verifiable outcomes - we provide three classroom examples of ways in which MTEs incorporated uncertainty into their mathematical tasks. Each example provides detail about the task design, background research on PTs' knowledge of the underlying mathematical content, the type of uncertainty the task generated for PTs, and the ways in which that uncertainty may have contributed to PTs' understandings of the content. Each example concludes with recommendations for MTEs on specific ways to incorporate that particular type of uncertainty into their own teaching.
\end{abstract}

Keywords: Mathematical tasks, prospective elementary teachers, mathematical knowledge for teaching, uncertainty, cognitive conflict

\section{Introduction}

The mathematical content preparation of elementary school teachers has received a great deal of attention from policy and research (Association of Mathematics Teacher Educators, 2017; Castro Superfine, Li, \& Martinez, 2013; Conference Board of the Mathematical Sciences, 
2012; Greenberg \& Walsh, 2008; Masingila, Olanoff, \& Kwaka, 2012; National Council of Teachers of Mathematics, 2014). Mathematics teacher educators (MTEs) charged with the content preparation of prospective teachers (PTs) grapple with a variety of issues, such as which mathematical topics to include in their courses and which pedagogical strategies to use to support PTs' learning. For example, it is now well accepted that PTs must learn with understanding the mathematics content that they will teach their future students in grades K-6 (Association of Mathematics Teacher Educators, 2017; Conference Board of the Mathematical Sciences, 2012). They also need repeated opportunities to engage in practices such as explaining, justifying, and making connections across ideas (Castro Superfine et al., 2013; National Council of Teachers of Mathematics, 2014). However, there remain questions regarding the kinds of curricular materials suitable for preparing elementary school teachers or the ways in which these materials may be implemented (Ball, Sleep, Boerst, \& Bass, 2009; Masingila et al., 2012).

Researchers also advocate developing PTs' mathematical knowledge for teaching (MKT), which is knowledge that is unique to the work of teaching and one that includes knowledge of content and pedagogy (Ball, Thames, \& Phelps, 2008; Hill, Rowan, \& Ball, 2005; Hill, Sleep, Lewis, \& Ball, 2007). An important component of this knowledge is specialized content knowledge (SCK), which is described as "an uncanny kind of unpacking of mathematics that is not needed - or even desirable - in settings other than teaching" (Ball et al., 2008, p. 400). SCK is more than simply knowing how to solve problems; it involves knowing how to explain, justify, and represent ideas in a variety of ways, evaluate the mathematical validity of students' responses, appreciate mathematical differences between strategies or interpretations, and recognize which examples can help make a particular mathematical argument (Ball et al., 2008). 
Although developing MKT is important, Ball and colleagues have also asserted that "no amount of pedagogical content knowledge can prepare a teacher for all of practice, for a significant proportion of teaching is uncertain" (Ball \& Bass, 2000, p. 89). Uncertainty is inherently a part of teaching, as teachers must be able to listen to, interpret, respond to, and discuss students' in-the-moment thinking as it emerges. While PTs can prepare to respond to many different student strategies, it is impossible to anticipate all strategies students might use. This is particularly true for new teachers who enact a lesson for the first time.

New teachers must possess the dispositions and flexibility to hear and respond to students' mathematical ideas. The Standards for Preparing Teachers of Mathematics (Association of Mathematics Teacher Educators, 2017) suggest that new teachers must be ready to nurture and support emergent mathematical ideas, so it is important for teacher preparation programs to prepare new teachers to productively respond to students' in-the-moment thinking. Ball and Bass (2000) discuss that we can help new teachers know in practice by working through situations in which they are uncertain to develop dispositions toward listening and actively working to interpret the mathematics at hand. They state:

Acknowledging the uncertainty of teaching does not mean that teachers cannot be prepared to know in practice. Quite the contrary: Knowing mathematics for teaching must take account of both the regularities and the uncertainties of practice, and must equip teachers to know in the contexts of the real problem they have to solve. (p. 90)

We hypothesize that teachers may hesitate to open up problems to student discussion partly because they are unsure if they will know or understand all strategies that might emerge. We argue that it is important, in content courses, to expose PTs to different types of uncertainty so that they develop dispositions to hear, interpret, and respond to unfamiliar ways of thinking. In addition, it also encourages PTs to question the mathematics they think they already know but 
may not fully understand, as well as broaden their own mathematical knowledge by considering alternative approaches.

In this paper, we focus specifically on uncertainty as it relates to mathematical task design and enactment in mathematics content courses for PTs. We use Zaslavsky's (2005) definition of uncertainty as consisting of conflict, doubt, confusion, or perplexity and her three types of uncertainty - competing claims, unknown path or questionable conclusion, non-readily verifiable outcomes - to show how uncertainty can be incorporated in mathematical tasks to support and develop PTs' SCK. We provide snapshots from our own content courses for PTs to illustrate three different ways in which introducing uncertainty into a mathematical task can foster PTs' learning. We also discuss implications for MTEs, including tools to support their design and enactment of mathematical tasks that incorporate uncertainty.

\section{Theoretical Framework: Uncertainty in Mathematical Tasks}

We define a mathematical task "as a classroom activity, the purpose of which is to focus students' attention on a particular mathematical idea" (Stein, Grover, \& Henningsen, 1996, p. 460). Tasks come in a variety of forms - from individual problems to sets of connected problems that help develop a particular idea. Different types of tasks can lead to different learning opportunities for PTs. Tasks that encourage reasoning about mathematical ideas or procedures have the potential to engage learners in fundamentally different kinds of mathematical thinking than, for instance, tasks that only promote the execution of step-by-step algorithms (Stein et al., 1996).

Numerous studies have described features of productive mathematical tasks (Castro Superfine, Prasad, Welder, Olanoff, \& Eubanks-Turner, 2020; Feldman et al., 2016; Ghosh Hajra, McNeal, \& Bowers, 2016; Hart, 2013; Mueller, Yankelewitz, \& Maher, 2010; Stein et al., 
1996; Suzuka et al., 2009; Zaslavsky, Watson \& Mason, 2007). These features include a focus on developing students' thinking and reasoning, exposure to multiple solution strategies and representations, adequate levels of complexity and challenge, authenticity and relevance to students' experiences or needs, and novel or unfamiliar contexts that serve as mechanisms for reconceptualizing previously learned content (Boaler \& Staples, 2008; Castro Superfine et al., 2020; Stein et al., 2009; Yackel, Underwood, \& Elias, 2007; Roscoe \& Feldman, 2015). Research has also provided information about tasks that can support PTs' specialized content knowledge (Suzuka et al., 2009; Feldman et al., 2016). For example, Suzuka et al. (2009) describe 'MKT tasks' whose features include unpacking ideas central to K-12 school curricula, an emphasis on explaining and justifying, and a purposefully planned stumble or challenge that compels PTs to rethink and deepen their understanding.

In this paper, we argue that injecting uncertainty into a mathematical task is another key feature of productive mathematical tasks. Since PTs enter their teacher preparation programs having had limited opportunities to move beyond traditional, procedurally-oriented, and inflexible understandings (Browning et al., 2014; Ball, 1990; Yang, Reys, \& Reys, 2009; Whitacre \& Nickerson, 2016), exposing PTs to situations of uncertainty may be useful in generating contradictions, provoking conflict, and fostering learning (Swars, 2006). Moreover, tasks that force PTs to grapple with uncertainty can promote learning through discussion and conflict resolution (Sayce, 2010).

We follow Zaslavsky's (2005) view of uncertainty as consisting of conflict, doubt, confusion, or perplexity. This perspective stems largely from Piaget's (1985) equilibration theory, which defines conflict as "psychological tension or perturbation that is created when an individual's expectations about a phenomenon do not accord with his or her observations or pre- 
conceived ideas" (Swan, Wake, \& Joubert, n. d., p. 1). This tension can lead the individual to reflect on their current understandings and make modifications that strengthen their understandings (Piaget, 1985; Hiebert \& Carpenter, 1992). Research and policy recommendations continue to describe the practice of providing learners with opportunities to struggle as a critical aspect of teaching and one that provides numerous benefits to learners (National Council of Teacher of Mathematics, 2014; Hiebert \& Grouws, 2007).

Zaslavsky (2005) identifies three types of uncertainty: competing claims, unknown path or questionable conclusion, and non-readily verifiable outcomes. Uncertainty generated from completing claims refers to conflicting or contradictory points of view resulting from a particular mathematical situation. This may include mathematical outcomes that conflict with the learner's previously held assumptions or beliefs, or tasks that present conflicting statements or arguments for the learner to resolve or reconcile (Zaslavsky, 2005). For example, consider the following task: A $6^{\text {th }}$ grade class is solving the following problem: "You have 5 pounds of jam that need to be packaged into 2/3-pound jars. How many jars of jam can you package?” Jaleesa got an answer of $71 / 2$ jars, but Emily got an answer of $71 / 3$ jars. Who is correct, and why? This problem can lead to uncertainty since students like Jaleesa will view the referent whole as 1 jar, while students like Emily will view the referent whole as 1 pound of jam. Uncertainty from an unknown path or questionable conclusion may result from work on open-ended and exploration tasks in which the learner does not know, in advance, the outcomes of the task and must develop, test, and potentially refine their conjectures (Zaslavsky, 2005). For example, determining which positive integers can be expressed as the sum of consecutive positive integers requires the learner to engage in an exploration of numerous examples in order to make conjectures. The learner likely has no prior knowledge of what the result might be, so they must continue to generate data 
in order to refine their conjectures. The third type of uncertainty, non-readily verifiable outcomes, refers to a lack of confidence stemming from a perceived inability to verify a solution to a problem (Zaslavsky, 2005). Oftentimes, probability tasks generate this type of uncertainty because checking the correctness of a solution may require considering too many individual events. Zaslavsky (2005) notes that these types are interrelated and subjective, meaning that one type of uncertainty could lead to or be triggered by another type, and that a task that may generate doubt or confusion for one learner may be simple and straight-forward for another.

Zaslavsky (2005) argues that engaging learners in tasks that generate any of the three types of uncertainties can help strengthen learners' mathematical sense making and problem solving abilities. We extend Zaslavsky's argument to propose that incorporating elements of uncertainty into mathematical task design can also support PTs' specialized content knowledge (SCK). In fact, we view SCK as the intersection of mathematical task design and uncertainty; by engaging future teachers in tasks that promote uncertainty, teacher educators can help them develop competencies around understanding other people's strategies. As Zaslavsky (2005) notes, implementing such tasks can engage teachers in "genuine learning experiences through which they become aware of their own learning processes and draw connections to their students' needs and difficulties" (p. 298).

This paper adds to the knowledge base around task design by describing how the purposeful use of uncertainty within mathematical tasks can support and develop PTs' SCK. In doing so, we argue that uncertainty is important for MTEs to consider when designing and enacting tasks in their courses. Snapshots from our content courses for PTs illustrate three different ways in which injecting uncertainty into a mathematical task can foster PTs' learning. Following the three classroom snapshots, we discuss implications for MTEs, including resources 
to support their design and enactment of mathematical tasks that promote elements of uncertainty.

\section{Classroom Example: Uncertainty as an 'Unknown Path'}

One way in which MTEs can introduce uncertainty into their curriculum is by implementing mathematical tasks with an unknown path or questionable conclusion. Zaslavsky (2005) describes this uncertainty as "a search for findings...that are unknown to the learner, for which he or she may or may not have an intuitive feeling regarding what to expect" (p. 302). The unknown path that the learner takes is often the result of an initial lack of awareness of what to expect. The purpose of such tasks is to compel the learner to make new discoveries, which may include identifying new patterns or connections.

We argue that posing tasks that generate uncertainty as an unknown path can support PTs' SCK. A component of SCK is the ability to present mathematical ideas and link particular representations to those ideas (Ball et al., 2008). Tasks that provide opportunities for PTs to venture down unknown paths may support their abilities to think about a mathematical idea in a different way or present that idea to students differently. Other ways of presenting content may include using various representations to model an underlying concept or attending to connections across related ideas.

The following is an example of a task used in a content course for PTs that generates uncertainty as an unknown path. The course was taught by the first author, a mathematics teacher educator, and offered by the mathematics department of a large research university in the northeastern U.S. The specific task focuses on strengthening PTs' knowledge and use of multiplicative structure as it pertains to the role of prime factorization in determining a number's divisibility. We follow Zazkis and Campbell's (1996a) definition of multiplicative structure as 
"conceptual attributes and relations pertaining to and implied by the decomposition of natural numbers as unique products of prime factors" (p. 541). Multiplicative structure is a foundational topic in the K-8 curriculum that underlies several important topics, including fractions, decimals, and algebra (Campbell, 2006; Brown, Thomas, \& Tolias, 2002).

Research on PTs' use of multiplicative structure reveals an overreliance on computationheavy procedures (Zazkis \& Campbell, 1996a). For example, when asked to determine whether $M=3^{3} \times 5^{2} \times 7$ is divisible by 7 , many PTs ignore the structure of $M$, and instead multiply the prime factors together and carry out long division. Several factors may contribute to this phenomenon, including a deeply held notion of a factor as one of exactly two whole numbers (i.e., a factor pair) whose product is their multiple, familiarity with long division, and limited opportunities to connect divisibility with prime factorization.

The following task was developed as part of a larger National Science Foundation funded curriculum development research project (Feldman \& Roscoe, 2018). A major goal of the task is to develop PTs' deep procedural knowledge (Star, 2005; Rittle-Johnson, Star, \& Durkin, 2012) of using prime factorization to determine a number's factors. The task first introduces PTs to the Fundamental Theorem of Arithmetic (Griffiths, 2013), and then gives the following prompt:

Find all the factor pairs of $N=2 \times 5 \times 7^{2}$ without first finding $N$.

A distinctive feature of the prompt is that it explicitly discourages PTs from relying on known solution methods, and instead, encourages them to use the prime factorization of $N$ to determine its factors. However, PTs' limited experience with prime factored form means that they often do not know how to approach the problem. Moreover, since the commonly used approach involves long division by trial and error, many PTs cannot anticipate what all of the 
factors might be. As such, the task creates some uncertainty for PTs as they begin to explore possible solution strategies without having a clear indication of how to proceed.

PTs work in small groups of 3-5 and are encouraged to share ideas and questions with their group. The instructor circulates, listening for various strategies that come up and occasionally asking groups questions in order to clarify or probe their thinking. It is critical, however, that the instructor does not reveal a correct strategy at this time so that PTs are forced to make and test their own conjectures about how prime factorization can help them find the number's factors. Initially, many are able to identify prime factors but not composite factors (Feldman \& Roscoe, 2018), claiming, for example, that “ $\ldots 2,5$, and 7 are factors of $N$ because they are in the prime factorization of $N$." If PTs believe that these are the only factors, the instructor can inform them that there are additional factors of $N$. This move injects additional uncertainty for PTs, as they must now develop a strategy to find composite factors.

This task illustrates the uncertainty of taking an unknown path by forcing PTs to attend to an unfamiliar representation in ways they have probably never considered. PTs' initial conjecture that 2, 5, and 7 are the sole factors of $N$ is incomplete, and must therefore be revised. Since they rarely consider products of prime factors as factors of $N$ (Feldman \& Roscoe, 2018), PTs struggle to make progress and may resort to previous methods like trial and error division. The instructor may at this point ask PTs to consider why 5 is a factor of $N$. PTs may notice that 5 is a factor of $N$ because when multiplied by another whole number (i.e., $2 \times 7^{2}$ ), the product is $N$. The instructor might then point out that since $2 \times 7^{2}$ is also a factor of $N$, then perhaps there are additional factors of $N$ that they must still find. This exchange often encourages PTs to coordinate two or more prime factors to find composite factors (e.g., $2 \times 5 \times 7$, or 70, is also a factor of $N$ ). This coordination is an example of how the prime factored form of a number can 
make a number's divisibility properties more transparent than its traditional whole number form (Zazkis \& Gadowsky, 2001). It also illustrates how the associative and commutative properties of multiplication underlie the process of determining composite factors.

Following small group work, the instructor facilitates a whole class discussion in which PTs share their strategies for finding all of the factors of $N$. A PT named Jessica presents the strategy of listing all factor pairs of $N$ (see Figure 1), after which the instructor asks several PTs to explain and justify Jessica's method. The following are snapshots of PTs' explanations and partial justifications of Jessica's strategy:

\begin{tabular}{|l|l|}
\hline $2(5 \times 7 \times 7)$ & 2,245 \\
$5(2 \times 7 \times 7)$ & 5,98 \\
$7(5 \times 2 \times 7)$ & 7,70 \\
$2 \times 5(7 \times 7)$ & 10,49 \\
$2 \times 7(5 \times 7)$ & 14,35 \\
$1(2 \times 5 \times 7 \times 7)$ & $1, N$ \\
\hline
\end{tabular}

Figure 1: PT-generated list of N's factor pairs.

Shelly: The first thing she did was expand all the numbers out, so every number was accounted for in a longer version, and then she just associated or grouped the numbers in all of the possible combinations that were there.

Jessica: [In response to a question about why her method works] Well, I think the commutative property. I mean, it doesn't matter which order you multiply the numbers, you still end up getting the same answer. 
Erica: She was looking for distinct groupings. So, after she finished pulling out one number, she moved on to two...so she was creating completely new, distinct, numbers that would be the factors. And then, after she pulled out two numbers, if she pulled out a third, it would be the same one she already did, so she was done.

An important feature of this task that can support PTs' SCK is its emphasis on justification (Ball et al., 2008). The strategy that Jessica developed for finding the factors of $N$ was based on the use of the commutative and associative properties of multiplication. Both Shelly and Jessica identify these properties as reasons for why her strategy is mathematically valid.

Erica further explains that one can use the prime factorization of a number to find all of its factors by finding increasingly larger combinations of prime factors (i.e., combinations of a single prime factor, two prime factors, three prime factors, etc.). This method allows PTs to keep track of all prime factor combinations. Developing a systematic approach for keeping track of all prime factor combinations can be challenging for PTs even after they determine that prime factors can be coordinated to find composite factors. Once PTs propose a list of $N$ 's factors, asking them to explain how they know they have found every factor often injects additional uncertainty, a questionable conclusion (Zaslavsky, 2005), that they must resolve. To resolve this issue, PTs can make a connection to a surprisingly related mathematical topic, combinatorics, by listing all combinations of $N$ 's prime factors.

This task supports PTs' abilities to make sense of multiplicative structure by forcing them to attend to a numerical representation with which they have had limited familiarity and asking strategic questions that leverage their prior knowledge. In this way, PTs have the opportunity to make connections between prime factorization and the underlying idea of divisibility. Along the 
way, they also begin to reconceptualize their prior notion of a factor of $N$, from either of two whole numbers whose product is $N$ to any whole number that can be represented as a product of $N$ 's prime factors.

Considering our repeated enactments of the task described above and prior research on PTs' attention to multiplicative structure (Feldman \& Roscoe, 2018; Zazkis \& Campbell, 1996a, 1996b), MTEs who wish to design or select tasks that promote mathematical exploration through unknown paths may wish to consider the following ideas:

- Pose problems that prohibit PTs' use of previously learned methods.

- Pose problems that attend to less familiar representations.

- Provide opportunities for PTs to make and test their own conjectures.

- Press PTs to construct mathematical justifications and make connections to what they already know.

As future teachers, PTs will be expected to teach mathematics in ways that may be unfamiliar to them. By engaging them in mathematical tasks with some of these characteristics, MTEs are helping PTs make sense of new ideas and strengthen their understanding of previously learned concepts.

\section{Classroom Example: Uncertainty as 'Competing Claims'}

MTEs can also interject uncertainty into mathematical tasks through the idea of competing claims. Competing claims involve two or more compelling approaches to the same task. Competing claims may be contradicting to each other or to a known mathematical truth, related to personal preferences or beliefs, or the exploration of a misconception. The purpose of competing claims is to help the mathematical learner to see mathematics from different perspectives and assess them for validity. 
We argue that posing competing claims is not only beneficial in learning mathematics as Zaslavsky (2005) suggests, but is also beneficial for the work of teaching. Ball, Thames, and Phelps (2008) identify one characteristic of SCK as mathematical knowledge that might include "looking for patterns in student errors or sizing up whether a non-standard approach would work in general" (p. 400). When analyzing competing claims, we argue that PTs are engaging in mathematical work that could help to build SCK because they are considering claims from multiple perspectives, including incomplete or incorrect ones, and unpacking mathematical concepts. This is similar to the work they will do in the classroom analyzing and unpacking students' mathematical claims.

The following example from a unit on area measurement provides a glimpse of what competing claims might look like in a course for PTs. Research on PTs' understanding of measurement topics suggests that they often approach measurement topics with limited understanding beyond procedures and formulas (Baturo \& Nason, 1996; Reinke, 1997). Measurement content provides an opportunity for PTs to wrestle with multiple solution strategies pertaining to a particular formula. One such task is the Lego Task, which we developed from research on elementary students' understanding of area (Barrett, Clements, \& Sarama, 2017) and our own research surrounding PTs' strategies for tiling area regions (Wickstrom, Fulton, \& Carlson, 2017). This task was enacted by the second author, a mathematics teacher educator, in a content course offered by the mathematics department of a large public research university in the western U.S. In the Lego task, PTs are given a Lego board and several different sized Lego pieces (see Figure 2). They are asked:

- How many of each Lego piece is needed to cover the board completely?

- What are different strategies you could use and why do they work? 


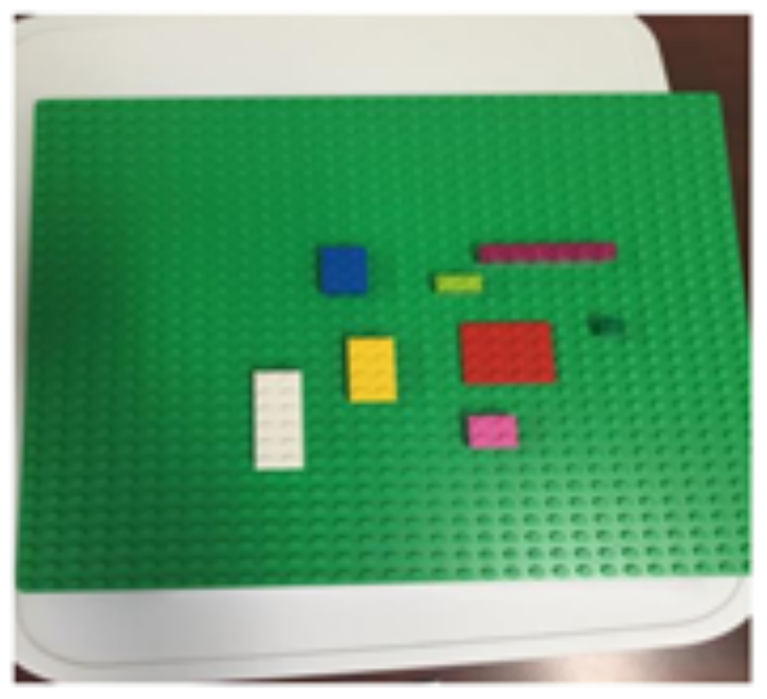

Figure 2: Lego board and pieces.

Legos are interesting tools to measure area because PTs have to make decisions on how to define and describe what they are measuring in the context of the situation including: defining the unit of measure, describing the pieces, and determining whether units are related to one another. The task elicits different strategies to tile a space and also allows PTs to grapple with strategies and solutions that might not seem familiar. Although there are many interesting strategies and claims that arise in this task, we will illustrate competing claims through an example that positions a PT's strategy against their "known" conceptions of the formula for finding rectangular area (length $\mathrm{x}$ width).

When measuring the $32 \times 32$ studded board, PTs usually recognize that it will take 256 $2 \times 2$ Lego pieces because 16 blocks span the length, 16 blocks span the width, and they can multiply 16 x 16 to determine it will be 256 pieces. In considering $2 \times 1$ Lego pieces, over half of the class will usually measure and conclude it also takes 2562 x 1 blocks because, as shown in Figure 3, it takes 16 pieces to span the width and the length of the board. In both cases, PTs claim that they have used the area formula to determine the required number of pieces and trust 
that it has provided an accurate solution. But, they are in conflict with one another. How can the same number of two Lego pieces of different sizes span the same amount of space?

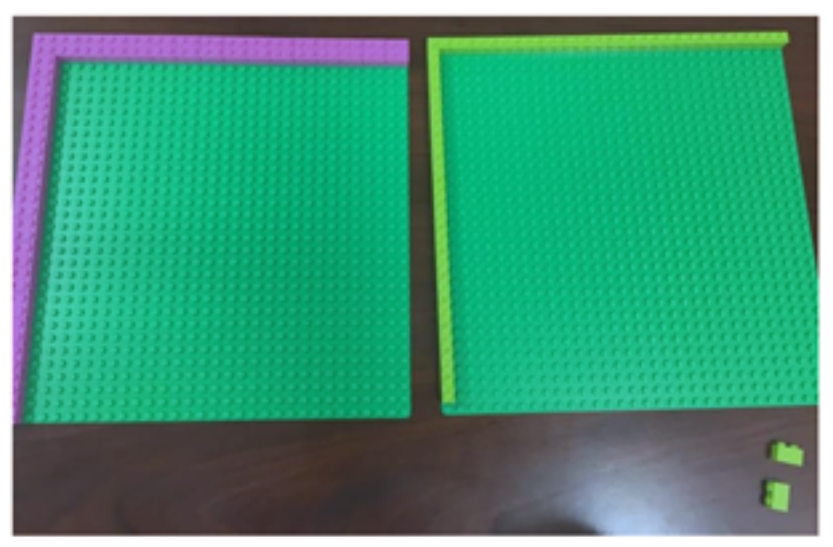

Figure 3: PTs' demonstration of how to use the area formula to find number of Legos needed.

At this point, PTs draw on other strategies, introducing more competing claims, such as: a) $2 \times 1$ is half as big as $2 \times 2$ so it should take twice as many Lego pieces (512), not the same amount; and, b) there are two studs on the $2 \times 1$ Lego. If I divide the total number of studs on the board by 2 to determine the number needed, I get 512 . The conflict generated by these competing claims provides an interesting space for PTs to question and further define the basis of our area formula, beyond length multiplied by width. At this point in the discussion, we ask PTs to explain why different solutions exist and how to reconcile them, to visually represent the strategy they implemented, and whether the area formula of "length times width" works in all cases.

When exploring the area formula strategy, PTs are forced to consider what length multiplied by width means in this context. Many begin to see the relationship between area measurement and the definition of multiplication. Length multiplied by width reflects groups (columns) and a quantity per group (rows). In considering their initial strategy, one PT stated, "we have to consider the length and the width of the pieces. Before when we laid it out as $16 \mathrm{x}$ 16, we were really doing length by length and ignoring the width of the Lego piece" (see Figure 
4). It is important to note in figure 4 that PTs purposefully did not have enough Legos to cover so they illustrated the orientation of the Legos and counted each empty space as a unit. Many PTs also discover and describe that, with square units, orientation does not matter because the length and width are identical. They are also forced to consider multiple strategies and approaches to determine which are valid and why.

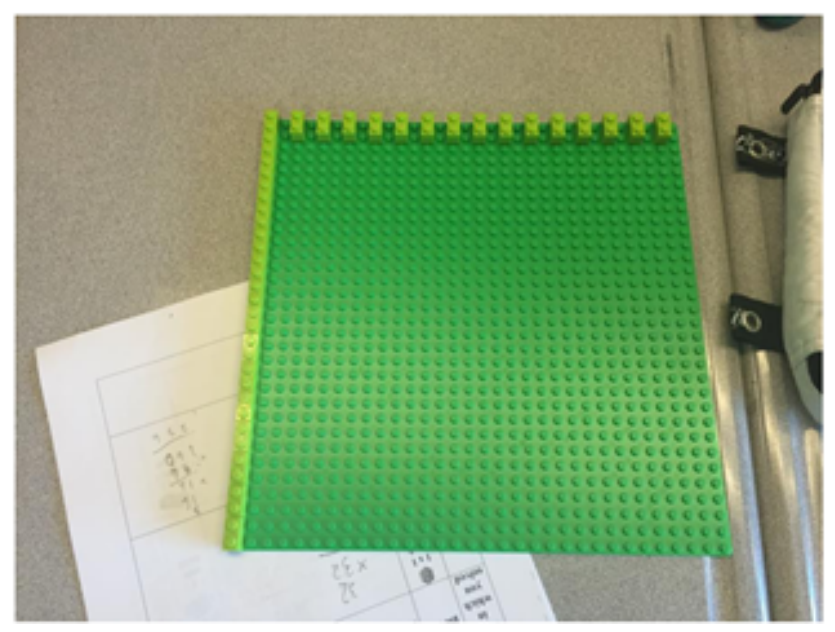

Figure 4: PTs reconstruction of $2 \times 1$ Legos in terms of multiplication.

Although on the surface, this task seems simple, the multitude of strategies available and the complexity generated by different sized units challenge PTs to make sense of an area formula that they often accept as true. By evaluating different claims, they begin to understand area and its formula in a more conceptual way.

In considering the Lego task, MTEs may wonder how they can find or design tasks that promote the use and evaluation of multiple competing claims. We offer the following ideas:

- Pose questions that have multiple solutions and have PTs evaluate one another's strategies

- Ask PTs to consider multiple representations of the same phenomenon 
- Raise contradicting solutions to what they know, through elementary student or peer samples

- Connect "known" or memorized mathematical facts (e.g., formulas) to their invented strategies

Through each of these practices, PTs are able to see mathematics beyond their own strategies. They are able to practice the work needed for teaching by unpacking mathematical ideas, potentially seeing connections, and determining the validity of claims.

\section{Classroom Example: Uncertainty as 'Non-readily Verifiable Outcomes'}

MTEs may also inject uncertainty into tasks through the idea of non-readily verifiable outcomes. This type of uncertainty involves the inability to verify or difficulty in verifying a solution of a task. Zaslavsky (2005) states that this "type of uncertainty has to do with the lack of confidence one may have regarding the correctness or validity of an outcome (e.g., solution to a problem) which requires verification" (p. 304). For example, one might use the invert-andmultiply algorithm to divide fractions, but if there is limited understanding as to why the algorithm makes sense, one may believe it is not possible to verify the outcome. The purpose of this type of uncertainty is to generate doubts so that the learner might reflect on their prior understandings in dealing with the task. We argue that encountering tasks with non-readily verifiable outcomes may lead PTs to (re)discover mathematical meanings and build SCK.

We will discuss the third type of uncertainty in the context of area measurement. Area measurement reflects a comparison of a shape and a given area-unit with a two-dimensional shape, as achieved by covering the shape with copies of the area-unit and counting how many area-units it takes to span the shape, without gaps or overlaps (Ghosh Hajra, McNeal, \& Bowers, 2016). Browning, Edson, Kimani, and Aslan-Tutak (2014) reviewed 112 published studies on 
PTs' geometric knowledge between 1984 and 2012 and found only 12 studies that deal specifically with area. The findings of all 12 studies indicate that PTs demonstrated "incorrect, incomplete, and unconnected" knowledge that was very "rule driven" (Browning et al., 2014, p. 344). A more recent study found that PTs struggle with the notion of area-units and do not recognize, for example, that an area measure quoted in square units refers to that number of square units needed to span a space (Ghosh Hajra et al., 2016). The study also reported that many PTs misused "units" "and/or phrases like "hexagonal regions squared" in reporting answers to area problems when measurements were taken using non-standard area-units (Ghosh Hajra et al., 2016; Ghosh Hajra \& McNeal, 2017).

PTs' challenges with area-units present a deeply-rooted conception that "square units do not conjure up an image of a square" (Simon \& Blume, 1994, p. 485). Baturo and Nason (1996) link this difficulty to limited notions of the attribute of area and emphasize that area should be considered from two perspectives: static and dynamic. The static perspective of area focuses on the amount of 2D space enclosed within a boundary. The dynamic perspective, however, describes "the relationship between the boundary of a shape and the amount of surface that it encloses so that, as the boundary approaches a line, the area approaches to zero" (p. 238).

The dynamic perspective is often missing from school curricula, which can limit students' understanding of area. Hence, it is important to develop tasks consisting of both perspectives that can challenge PTs' thinking of area-units (Baturo \& Nelson, 1996). The tasks discussed below attend to both perspectives with respect to the use of non-standard units, the idea of breaking units into small pieces to fill a space, and the idea that smaller pieces lead to more precise estimates for area. In particular, after fitting a shape with the whole area-units, the spaces left near the boundary of a shape can be filled in with smaller and smaller pieces of the area-unit. 
The idea is that as one gets closer to the boundary, the portion of the area-unit that goes in to fill in that space becomes smaller.

Let us now consider some area-unit tasks for PTs that contain non-readily verifiable outcomes. One such task asks PTs to use different shapes of post-it notes as area-units to measure a shape with non-linear boundaries (see Figure 5). PTs work in groups where each group is given a set of particular shaped post-it notes, the same 2D region, and the following prompts:

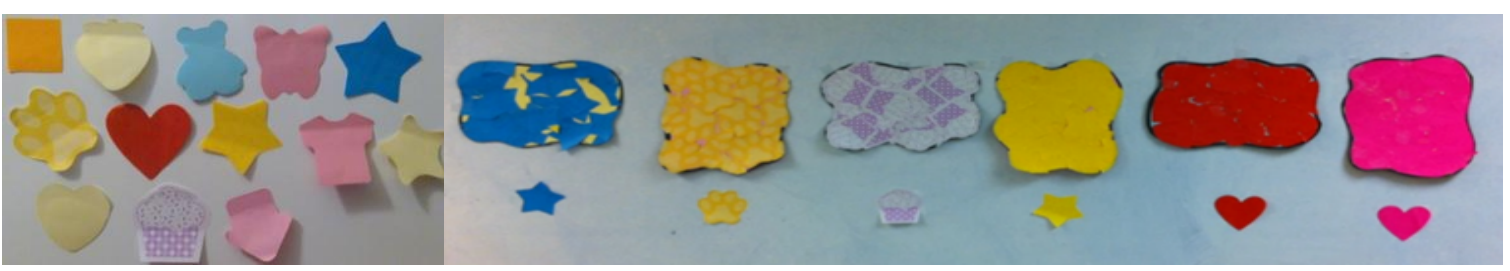

Figure 5: Left: different shaped post-it notes; Right: 2D-shapes covered with post-it notes.

\section{Area-unit task 1: Making sense of area of a shape using non-standard area-units.}

a) How many post-it notes would fit in the given $2 D$ region? How did you decide on the numerical value? Discuss your strategies.

b) What is the area of the given 2D-region (from part (a)) when the area-unit is a pawshaped post-it note, a heart-shaped post-it note, a t-shirt-shaped post-it note, and a starshaped post-it note (refer to the solutions of part (a) on the whiteboard)? Report precisely the area-unit along with the numerical value.

This task was taught in a content course for PTs by the third author, a mathematics faculty member at a public research university in the western U.S. PTs share their answers to part (a) on a whiteboard, and then work in groups on part (b).

This task reflects uncertainty as a non-readily verifiable outcome because PTs cannot verify their solution strategies using known area formulas. One strategy that PTs use is to cover 
the shape with whole post-it notes, cut along the boundary of the shape to remove any extra portions of post-it notes, and then count the number of whole post-it notes used less the estimated fractions of extra pieces that were cut off (see Figure 6, left). A second strategy used is to cover the shape with one post-it note at a time before using another post-it note, either by fitting or a combination of tearing apart and fitting, and then estimate the area of the shape by counting the number of post-it notes that are used, both whole and fractional post-it notes (see Figure 6, right). Area-unit Task 1 emphasizes the importance of using estimation to determine area with non-standard units. PTs report their solutions in terms of post-it notes area-units, which can reinforce the notions of area-unit as a unit of measurement, area measurement as a comparison between a space and a unit of measurement, and the importance of not overlapping or leaving gaps between area-units.
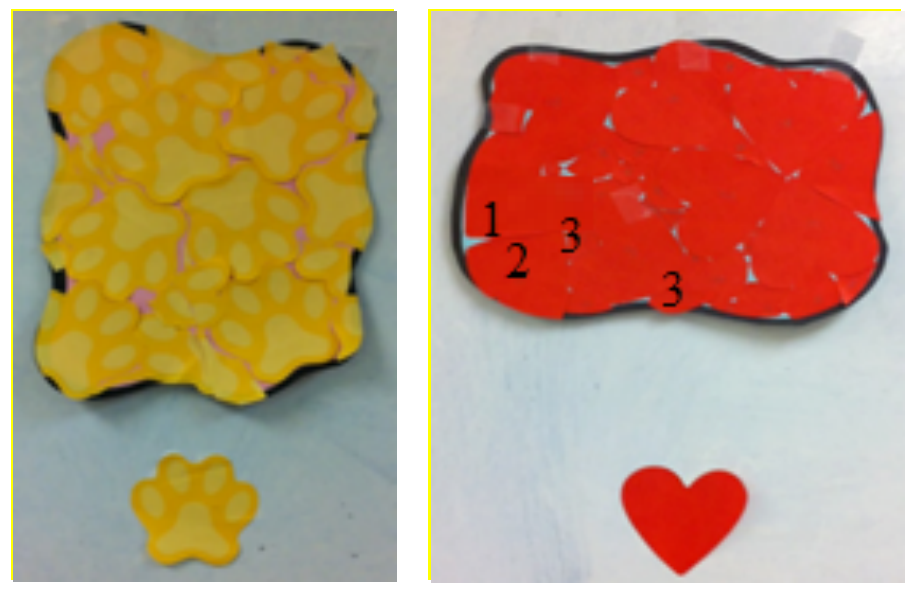

Figure 6. Left: Strategy 1. Covering by whole post-it notes first and then cutting along the boundary; Right: Strategy 2. Using one post-it note completely, before using the next one. Counting has been shown.

A second task, meant to follow the first, asks PTs to use a polygonal area-unit to find the area of a region bounded by a circle (see Figure 7). 


\section{Task 2: Polygonal area-unit task.}

a) How many polygonal area-units would fit in the region enclosed by the circle?

b) What is the area of the above region enclosed by the circle using just one of the squares as the area-unit? Specify the area-unit in reporting the area. What is the area of the region using the area formula of a circle? Does the answer from part (a) match with the answer using the area formula? What can be concluded about the area-unit used in the area-formula of a circle?

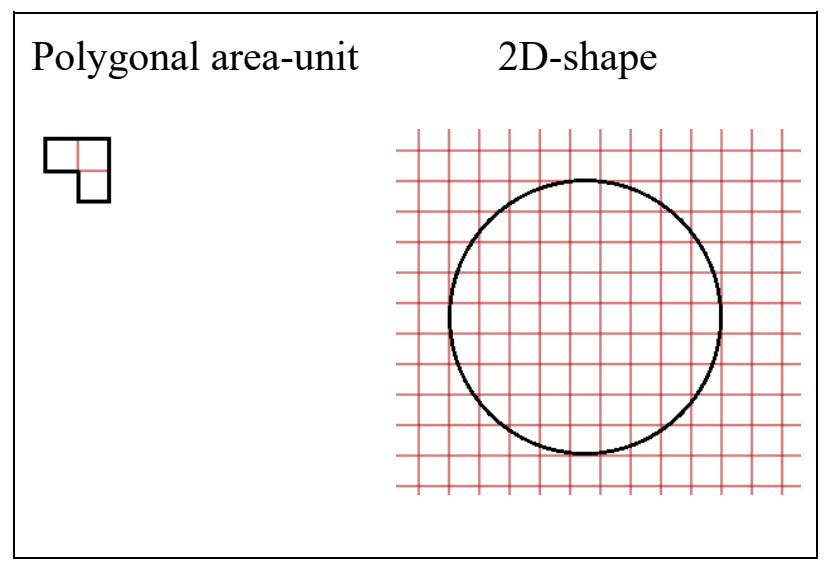

Figure 7: Finding the area of a region enclosed by a circle using a polygonal area-unit.

In an earlier version of Task 2 (Ghosh Hajra \& McNeal, 2017), PTs were asked to estimate the area of the region enclosed by the circle using the polygonal area-unit. The majority of PTs used the area formula of a region bounded by a circle, $\pi(4.5)^{2} \approx 64$, not realizing that this formula implies that the unit of comparison is a square unit. Hence, the task was modified to first ask for the number of polygonal area-units that would fit in the region bounded by the circle. We have seen PTs use counting and covering methods to solve the task. One method is to work with the area-unit rigidly without breaking it apart, cover the circular region, count, and subtract the estimated extra area. Another method is to count all the square units in the circle and divide by 3 , which is approximately 21 polygonal area-units. PTs quickly find that the area formula gives a 
different answer than when using the given polygonal area-unit, creating a moment of uncertainty that leads to a consideration of appropriate area-units. This task is followed by class discussion about the circumstances in which a square unit is or is not appropriate.

These tasks were developed to help PTs make sense of the notion of area as a covering, as well as to reinforce the idea of decomposing and moving units when estimating area as the number of area-units. Specifically, the tasks allow PTs to reconsider area as a comparison with standard or non-standard area-units. For example, most PTs recognize that an area measure of 10 $\mathrm{m}^{2}$ implies that there are ten $1 \mathrm{~m}-$ by- $1 \mathrm{~m}$ squares covering the shape. After completing both tasks, many PTs state that when asked about area "it is tempting to say area is length times width, but it is not always true; area is the number of the area-units present within a shape." The uncertainty that both tasks generated challenged PTs' preconceived notion of area formulas and provided opportunities for PTs to develop a more robust understanding of area.

In considering the area-unit task, we offer MTEs the following suggestions for designing tasks to include non-readily verifiable outcomes:

- Pose tasks that address PTs' common errors related to definitions of important mathematical concepts

- Pose tasks in which the solution is not known and engaging in the task involves making choices and assumptions.

- Pose multiple variations of a task reiterating the same ideas

- Connect notations used in mathematics with their meanings.

\section{Discussion}

PTs' mathematical learning is often characterized as passing through some level of uncertainty towards deeper mathematical understanding, new perspectives, and connections 
across content domains. When discussing reflective thinking, Dewey (1933) states that "the origin of thinking is some perplexity, confusion, or doubt" (p. 15). Principles to Action (National Council of Teachers of Mathematics, 2014) calls for productive struggle to be one of the principles for mathematical success. At the same time, the Standards for Preparing Teachers of Mathematics (Association of Mathematics Teacher Educators, 2017) suggests that learning mathematics for teaching should involve engaging in particular mathematical practices such as reasoning, sense making, connection-making, and problem solving.

Looking across our three examples, we observed that incorporating elements of uncertainty into our mathematical tasks provided opportunities for PTs to engage in the practices described above. These experiences reflect Zaslavsky's (2005) claim that small changes to tasks can bring about uncertainty, and subsequently, productive learning. Across our three examples, restricting the use of familiar tools or strategies (e.g., trial and error division, area formulas) forced PTs to explore unknown solution pathways and make connections between commonly held mathematical truths and new ideas. Additionally, by giving PTs tools with which they were unfamiliar (e.g., prime factorization, non-standard area-units), the tasks provided opportunities for PTs to reconceptualize mathematical ideas by forcing them to (re)consider outcomes that they cannot check instantaneously or about which they have limited to no intuition. While our tasks did not use this approach, MTEs can also introduce uncertainty by drawing on elementary students' or PTs' work samples (including both correct and incorrect work). Doing so can serve as a good starting point for generating competing claims, as PTs are forced to reconsider or justify their solution strategy for a task through the lens of an alternative strategy or representation. See Max and Welder (2020) for strategies and resources for using artifacts of children's thinking. 
Injecting uncertainty into mathematical tasks may have the added benefit of stimulating curiosity and cultivating persistence in reasoning about mathematical topics. PTs who enter our classes often believe that they already know and understand the mathematics needed to teach elementary school mathematics (Thanheiser, Philipp, Fasteen, Strand, \& Mills, 2013). Enacting tasks that provoke uncertainty allows PTs to question what they know to be true and, in the process, fosters an environment in which uncertainty and errors are accepted and perhaps even welcomed as opportunities for learning.

Tasks that include uncertainty allow instructors to address various practice standards (Association of Mathematics Teacher Educators, 2017; National Council of Teachers of Mathematics, 2014) at the same time through engaging problems that provoke PTs' curiosity and reasoning. In each of the three examples above, PTs engaged in reasoning and sense-making to understand a mathematical idea from a different perspective. Their conceptions about the mathematics were questioned, and they were pushed to explain their thinking and the thinking of their classmates. These elements are integral components of SCK and have the potential to help PTs unpack mathematical ideas to better understand the mathematics that they will teach to their future students. By explicitly considering uncertainty as a feature of task design, MTEs can integrate various types of uncertainty into their materials to encourage their PTs to grapple with concepts from multiple perspectives and support PTs' SCK development.

\section{References}

Association of Mathematics Teacher Educators. (2017). Standards for preparing teachers of mathematics. Retrieved from http://www.amte.net/standards.

Ball, D. L. (1990). The mathematical understandings that prospective teachers bring to teacher education. Elementary School Journal, 90, 449-466. 
Ball, D. L. (1991). Research on teaching mathematics: Making subject matter part of equation, in J. Brophy (ed.), Advances in research on teaching: Vol. 2. Teachers' knowledge of subject matter as it relates to their teaching practices, JAI Press, Greenwich, pp. 1-48.

Ball, D. L., \& Bass, H. (2000). Interweaving content and pedagogy in teaching and learning to teach: Knowing and using mathematics. In J. Boaler (Ed.), Multiple perspectives on mathematics teaching and learning (pp. 83-104). Westport, CT: Ablex Publishing.

Ball, D. L., Sleep, L., Boerst, T. A., \& Bass, H. (2009). Combining the Development of Practice and the Practice of Development in Teacher Education. The Elementary School Journal, Vol. $109(5)$, pp. $458-474$

Ball, D. L., Thames, M. H., \& Phelps, G. (2008). Content knowledge for teaching: What makes it special? Journal of Teacher Education, 59, 389-407.

Barrett, J. E., Clements, D. H. \& Sarama, J. (2017). Children's measurement: A longitudinal study of children's knowledge and learning of length, area, and volume. (JRME Monograph No. 16). Reston, VA: National Council of Teachers of Mathematics.

Baturo, A., \& Nason, R. (1996). Student teachers' subject matter knowledge within the domain of area measurement. Educational Studies in Mathematics, 31(3), 235-268.

Boaler, J., \& Staples, M. (2008). Creating mathematical futures through an equitable mathematics approach: The case of Railside School. Teachers College Record, 110(3), 608645.

Brown, A, Thomas, K., \& Tolias, G. (2002). Conceptions of divisibility: Success and understanding. In S. R. Campbell \& R. Zazkis (Eds.), Learning and teaching number theory: Research in cognition and instruction (pp. 41-82). Westport, CT: Ablex Publishing. 
Browning, C., Thanheiser, E., Edson, A. J., Kimani, P. M., Olanoff, D., Tobias, J. M., \& Whitacre, I. (2014). Prospective elementary mathematics teacher content knowledge: An introduction. The Mathematics Enthusiast, 11(2), 203-216.

Campbell, S. R. (2006). Understanding elementary number theory in relation to arithmetic and algebra. In R. Zazkis \& S. R. Campbell (Eds.), Number theory in mathematics education: Perspectives and prospects (pp. 19-40). Mahwah, NJ: Lawrence Erlbaum Associates, Inc.

Castro Superfine, A., Li, W., \& Martinez, M. (2013). Developing preservice teachers' mathematical knowledge for teaching: Making explicit design considerations for a content course. Mathematics Teacher Educator, 2(1), 42-54.

Castro Superfine, A., Prasad, P. V., Welder, R. M., Olanoff, D., \& Eubanks-Turner, C. (2020). Exploring mathematical knowledge for teaching teachers: Supporting prospective teachers' relearning of mathematics. In A. Appova, R. M. Welder, and Z. Feldman, (Eds.), Supporting Mathematics Teacher Educators' Knowledge and Practices for Teaching Content to Prospective (Grades K-8) Teachers. Special Issue: The Mathematics Enthusiast, ISSN 15513440, vol. 17, nos. 2 \& 3, pp. 367-402. ScholarWorks: University of Montana. Retrieve (open access) from: https://scholarworks.umt.edu/tme

Conference Board of the Mathematical Sciences. (2012). The mathematical education of teachers II. Providence RI and Washington DC: American Mathematical Society and Mathematical Association of America.

Dewey, J. (1933). How we think: A restatement of the relation of reflective thinking to the educative process. Boston, MA: D.C. Heath and Co.

Feldman, Z., \& Roscoe, M. B. (2018). Encouraging teachers to make use of multiplicative structure. Mathematics Teacher Educator, 7(1), 60-85. 
Feldman, Z., Thanheiser, E., Welder, R. M., Tobias, J. M., Hillen, A. F., \& Olanoff, D. (2016). When is a mathematical task a good task? In L. Hart, S. Oesterle, S. Swars, \& A. Kajander (Eds.), The mathematics education of elementary teachers: Issues and strategies for content courses (pp. 9-24). Charlotte, NC: IAP - Information Age Publishing, Inc.

Ghosh Hajra, S., McNeal, B., \& Bowers, D. (2016). Pre-service teachers' meanings of area. In (Eds.) T. Fukawa-Connelly, N. Infante, M. Wawro, and S. Brown, Proceedings of the 19th Annual Conference on Research in Undergraduate Mathematics Education (pp. 800-807). Pittsburgh, Pennsylvania.

Ghosh Hajra, S., \& McNeal, B. (2017). Exploring a pre-service teacher's conceptions of area and area units. In (Eds.) A. Weinberg, C. Rasmussen, J. Rabin, M. Wawro, and S. Brown, Proceedings of the 20th Annual Conference on Research in Undergraduate Mathematics Education (pp. 613-620). San Diego, California.

Greenberg, J., \& Walsh, K. (2008). No common denominator: The preparation of elementary teachers in mathematics by America's education schools. Washington DC: National Council on Teacher Quality.

Griffiths, M. (2013). Intuiting the fundamental theorem of arithmetic. Educational Studies in Mathematics, 82, 75-96.

Hart, L. (2013). Pedagogical content analysis of mathematics as a framework for task design. In C. Margolinas (Ed.), Task design in mathematics education. Proceedings of ICMI Study 22 (pp. 337-345). Oxford, England, ICMI.

Hiebert, J., \& Carpenter, T. P. (1992). Learning and teaching with understanding. In D. A. Grouws (Ed.), Handbook of research on mathematics teaching and learning (pp. 65-97). Reston VA: National Council of Teachers of Mathematics. 
Hiebert, J., \& Grouws, D. A. (2007). The effects of classroom mathematics teaching on students' learning. In F.K. Lester (Ed.), Second handbook of research on mathematics teaching and learning (pp. 371-404). Reston, VA: National Council of Teachers of Mathematics.

Hill, H. C., Rowan, B., \& Ball, D. L. (2005). Effects of mathematical knowledge for teaching on student achievement. American Educational Research Journal, 42, 371-406.

Hill, H. C., Sleep, L., Lewis, J. M., \& Ball, D. L. (2007). Assessing teachers' mathematical knowledge: What knowledge matters and what evidence counts? In F. Lester (Ed.), Second handbook of research on mathematics teaching and learning (pp. 111-156). Charlotte, NC: Information Age Publishing.

Kilpatrick, J., Swafford, B. \& Findell, B. (2001). Adding It Up: Helping Children Learn Mathematics. National Research Council.

Masingila, J. O., Olanoff, D. E., \& Kwaka, D. K. (2012). Who teaches mathematics content courses for prospective elementary teachers in the United States? Results of a national survey. Journal of Mathematics Teacher Education, 15(5), 347-358.

Max, B. \& Welder, R. M. (2020). Mathematics teacher educators' addressing the common core standards for mathematical practice in content courses for prospective elementary teachers: A focus on critiquing the reasoning of others. In A. Appova, R. M. Welder, and Z. Feldman, (Eds.), Supporting Mathematics Teacher Educators' Knowledge and Practices for Teaching Content to Prospective (Grades K-8) Teachers. Special Issue: The Mathematics Enthusiast, ISSN 1551-3440, vol. 17, nos. 2 \& 3, pp. 843-881. ScholarWorks: University of Montana. Retrieve (open access) from: https://scholarworks.umt.edu/tme

McDiarmid, G. W. (1988). The liberal arts: Will more result in better subject matter understanding. Theory into Practice 29(1), 21-29. 
Mueller, M. F., Yankelewitz, D., \& Maher, C. (2010). Promoting student reasoning through careful task design: A comparison of three studies. International Journal for Studies in Mathematics Education, 3(1), 135-156.

National Council of Teachers of Mathematics (2014). Principles to actions: Ensuring mathematical success for all. Reston, VA: Author.

Piaget, J. (1985). The equilibration of cognitive structures: the central problem of intellectual development. Chicago: University of Chicago Press.

Reinke, K. S. (1997). Area and perimeter: Preservice teachers' confusion. School Science and Mathematics, 92(2), 75-77.

Rittle-Johnson, B., Star, J. R., \& Durkin, K. (2012). Developing procedural flexibility: Are novices prepared to learn from comparing procedures? British Journal of Educational Psychology, 82, 436-455.

Roscoe, M. B., \& Feldman, Z. (2015). Strengthening prospective elementary teachers' Understanding of Factors. In S. M. Che, \& K. A. Adolphson (Eds.), Proceedings of the $42^{\text {nd }}$ Annual Meeting of the Research Council on Mathematics Learning (pp. 17-24). Las Vegas, NV: RCML.

Sayce, L. (2010). The way out of cognitive conflict: A planning toolkit for teachers. Retrieved from https://www.ncetm.org.uk/public/files/695450/TEFP0901+Toolkit+The+Way+Out+of+ Cognitive+Conflict.pdf

Simon, M., \& Blume, G. (1994). Building and understanding multiplicative relationships: A study of prospective elementary teachers. Journal for Research in Mathematics Education, $25(5), 472-494$. 
Smith, M., \& Stein, M. K. (2011). 5 practices for orchestrating productive mathematics discussions. Reston, VA: National Council of Teachers of Mathematics.

Star, J. R. (2005). Reconceptualizing procedural knowledge. Journal for Research in Mathematics Education, 36(5), 404-411.

Stein, M. K., Grover, B. W., \& Henningsen, M. (1996). Building student capacity for mathematical thinking and reasoning: An analysis of mathematical tasks used in reform classrooms. American Educational Research Journal, 33(2), 455-488.

Stein, M. K., Smith, M. S., Henningsen, M., \& Silver, E. A. (2009). Implementing standardsbased mathematics instruction: A casebook for professional development. New York: Teachers College Press.

Suzuka, K., Sleep, L., Ball, D., Bass, H., Lewis, J. M., \& Thames, M. H. (2009). Designing and using tasks to teach mathematical knowledge for teaching. In D. S. Mewborn \& H. S. Lee (Eds.), Scholarly practices and inquiry in the preparation of mathematics teachers (AMTE monograph series, volume 6) (pp. 7-23). San Diego, CA: Association of Mathematics Teacher Educators.

Swan, M., Wake, G., \& Joubert, M. (n. d.). FaSMEd Position Paper.

Thanheiser, E., Philipp, R.A., Fasteen, J., Strand, K., \& Mills, B. (2013). Preservice-teacher interviews: A tool for motivating mathematical learning. Mathematics Teacher Educator, 1(2), $137-147$.

Whitacre, I., \& Nickerson, S. D. (2016). Prospective elementary teachers making sense of multidigit multiplication: Leveraging resources. Journal for Research in Mathematics Education, 47(3), 270-307. 
Wickstrom, M. H., Fulton, E.W., \& Carlson, M. A. (2017). Pre-service teachers' conceptions of tiling and relating area units. Journal of Mathematical Behavior, 48(4), 112-136.

Yackel, E., Underwood, D., \& Elias, N. (2007). Mathematical tasks designed to foster a reconceptualized view of early arithmetic. Journal for Mathematics Teacher Education, 10(4-6), 351-367.

Yang, D.-C., Reys, R. E., \& Reys, B. J. (2009). Number sense strategies used by pre-service teachers in Taiwan. International Journal of Science and Mathematics Education, 7, 383403.

Zazkis, R., \& Campbell, S. R. (1996a). Divisibility and multiplicative structure of natural numbers: Pre-service teachers' understanding. Journal for Research in Mathematics Education, 27(5), 540-563.

Zazkis, R., \& Campbell, S. R. (1996b). Prime decomposition: Understanding uniqueness. Journal for Mathematical Behavior, 15, 207-218.

Zaslavsky, O. (2005). Seizing the opportunity to create uncertainty in learning mathematics. Educational Studies in Mathematics, 60, 297-321.

Zaslavsky, O., Watson, A., \& Mason, J. (Eds.). (2007). The nature and role of tasks in mathematics teachers' education. Journal of Mathematics Teacher Education, 10, 201-440. 